\title{
A Survey of Frequency and Voltage Control Ancillary Services-Part I: Technical Features
}

\author{
Yann G. Rebours, Student Member, IEEE, Daniel S. Kirschen, Fellow, IEEE, Marc Trotignon, and \\ Sébastien Rossignol
}

\begin{abstract}
This two-part paper surveys the frequency and voltage control ancillary services in power systems from various parts of the world. In this first part, the nomenclature used to describe active power reserves across 11 systems is first reviewed in order to facilitate the comparison of frequency control ancillary services. The essential technical features of frequency and voltage control ancillary services are then described. Finally, the technical requirements adopted in eight jurisdictions (North America, continental Europe, Germany, France, Spain, the Netherlands, Belgium, and Great Britain) are compared. The companion paper surveys the economic features of these ancillary services.
\end{abstract}

Index Terms-Ancillary services, frequency control, reactive power, spinning reserve, system services, voltage control.

\section{INTRODUCTION}

C ONTROLLING frequency and voltage has always been an essential part of operating a power system. However, since the liberalization of the electricity supply industry, the resources required to achieve this control have been treated as services that the system operator has to obtain from other industry participants. Because this liberalization has proceeded independently in different parts of the world and because of the structural differences in the underlying power systems, the technical definitions of these services and the rules governing their trading vary considerably. The objectives of this paper and its companion [1] are to survey these differences and provide a sound basis for comparisons. This paper focuses on the definitions and technical characteristics of the frequency and voltage control ancillary services in the 11 power systems shown in Table I. This table also shows the abbreviation used in this paper to refer to each system, the name of the regulatory authority, and the name of the transmission system operator (TSO). The companion paper surveys the economic features of trading in these ancillary services.

\section{NOMENCLATURE}

The profusion of terms used for ancillary services may lead to some misunderstandings and confusion when one tries to compare services from different power systems or jurisdictions. This section establishes a common framework, which is then used to classify the services considered in this survey. This framework

Manuscript received April 6, 2006; revised August 9, 2006. This work was supported by Electricité de France (EDF). Paper no. TPWRS-00197-2006.

Y. G. Rebours and D. S. Kirschen are with the University of Manchester, Manchester M60 1QD, U.K. (e-mail: yann.rebours@ieee.org; daniel.kirschen@ manchester.ac.uk).

M. Trotignon and S. Rossignol are with EDF Research and Development, Clamart 92141 Cedex, France (e-mail: marc.trotignon@edf.fr; sebastien. rossignol@edf.fr).

Digital Object Identifier 10.1109/TPWRS.2006.888963
TABLE I

SyStEMS INCLUDED IN THE SURVEY OF TECHNICAL FEATURES

\begin{tabular}{l|c|c|c}
\hline \multicolumn{1}{c|}{ System } & Abbreviation & Regulator & TSO \\
\hline Australia & AU & AER & NEMMCO \\
\hline Belgium & BE & CREG & Elia \\
\hline California & CAL & FERC & CAISO \\
\hline France & FR & CRE & RTE \\
Germany & DE & BNA & $\begin{array}{c}\text { EnBW, E.ON, } \\
\text { RWE and VET }\end{array}$ \\
\hline Great Britain & GB & Ofgem & NGET \\
\hline The Netherlands & NL & DTe & TenneT \\
\hline New Zealand & NZ & $\begin{array}{c}\text { Electricity } \\
\text { Commission }\end{array}$ & Transpower \\
\hline PJM & PJM & FERC & PJM ISO \\
\hline Spain & ES & CNSE & REE \\
\hline Sweden & SE & Stem & SvK \\
\hline
\end{tabular}

is based on the one used by the Union for the Co-ordination of Transmission of Electricity (UCTE), which is the association of the TSOs operating within the synchronous system of mainland Europe. The UCTE establishes the security and reliability standards for this interconnected system. Its activities are thus comparable to those of the North American Electric Reliability Council (NERC). However, like NERC, the UCTE is not a system operator and hence does not intervene in the operational working of the system.

\section{A. Frequency Control Services}

Maintaining the frequency at its target value requires that the active power produced and/or consumed be controlled to keep the load and generation in balance. A certain amount of active power, usually called frequency control reserve, is kept available to perform this control. The positive frequency control reserve designates the active power reserve used to compensate for a drop in frequency. On the other hand, the deployment of negative frequency control reserve helps to decrease the frequency.

Three levels of controls are generally used to maintain this balance between load and generation [3]-[8], [37]. Primary frequency control is a local automatic control that adjusts the active power generation of the generating units and the consumption of controllable loads to restore quickly the balance between load and generation and counteract frequency variations [3]-[5]. In particular, it is designed to stabilize the frequency following large generation or load outages. It is thus indispensable for the stability of the power system. All the generators that are located in a synchronous zone and are fitted with a speed governor perform this control automatically. The demand side also participates in this control through the self-regulating effect of frequency-sensitive loads such as induction motors [3], [4] or the action of frequency-sensitive relays that disconnect or connect some loads at given frequency thresholds. However, this 
TABLE II

NAMES OF THE FreQuency CONTROL RESERVES IN THE SySTEMS INCLUDED IN THE SURVEy

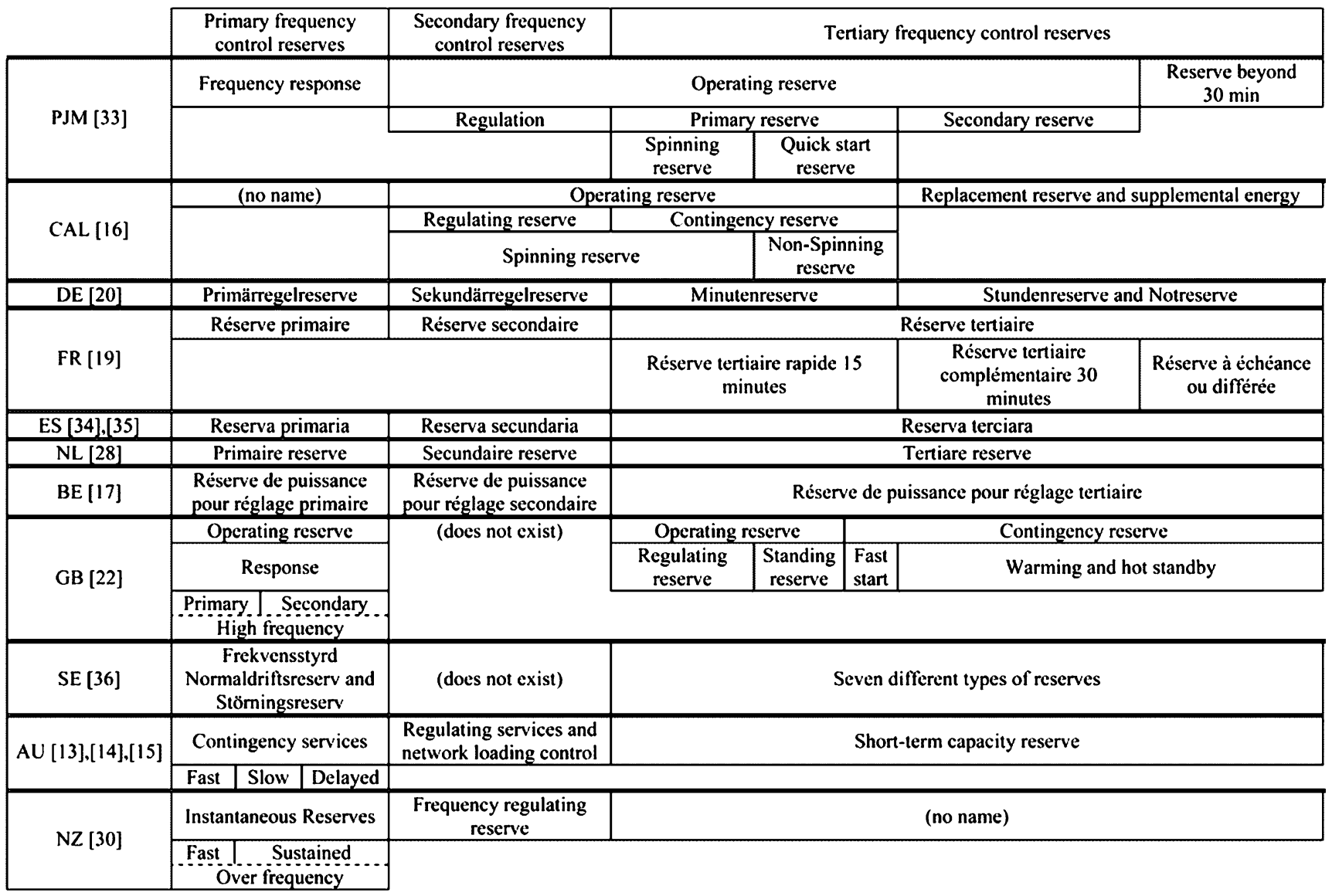

demand-side contribution is not always taken into account in the calculation of the primary frequency control response [37]. The provision of this primary control is subject to some constraints. Some generating units that increase their output in response to a frequency drop cannot sustain this response for an indefinite period of time. Their contribution must therefore be replaced before it runs out. It is also important that the contributors to primary control be distributed across the interconnected network to reduce unplanned power transits following a large generation outage and enhance the security of the system. In addition, a uniform repartition helps maintain the stability of islanded systems in case of a power system separation.

Secondary frequency control is a centralized automatic control that adjusts the active power production of the generating units to restore the frequency and the interchanges with other systems to their target values following an imbalance [6], [7]. In other words, while primary control limits and stops frequency excursions, secondary control brings the frequency back to its target value. Only the generating units that are located in the area where the imbalance originated should participate in this control as it is the responsibility of each area to maintain its load and generation in balance. Note that loads usually do not participate in secondary frequency controls. Contrary to primary frequency control, frequency secondary control is not indispensable. This control is thus not implemented in some power systems where the frequency is regulated using only automatic primary and manual tertiary control. However, secondary frequency control is used in all large interconnected systems because manual control does not remove overloads on the tie lines quickly enough. Within the UCTE, secondary frequency control is also called load-frequency control (LFC) [37], while the term automatic generation control (AGC) is preferred in North America [25]. However, within the UCTE, the term AGC designates the combination of dispatching and secondary frequency control [37]. Lastly, synchronous time is controlled by adjusting the target frequency used in the secondary frequency control [37].

Tertiary frequency control refers to manual changes in the dispatching and commitment of generating units. This control is used to restore the primary and secondary frequency control reserves, to manage congestions in the transmission network, and to bring the frequency and the interchanges back to their target value when the secondary control is unable to perform this last task. Some aspects of tertiary control relate to the trading of energy for balancing purposes. This paper does not deal with these aspects because they do not represent a service provided to the TSO by the market participants but a mechanism for the participants to balance their financial positions.

Table II compares the nomenclature used to describe the reserves associated with each type of frequency control in the systems included in this survey. The names are shown in the original languages to avoid misinterpretation. In this table, for each type of control, the reserves are ordered from the fastest (left) to the slowest (right). Reserves within a given column are thus similar. Within a system, terms are classified from the most gen- 
eral (top) to the most specific (bottom). A dashed line means that positive and negative reserves have different names. For instance, in Great Britain, the terms "primary response" and "secondary response" are used for the positive primary frequency control reserve and "high frequency response" for the negative one. In some cases (e.g., Australia), the name of a service may be used as the corresponding reserve does not have a name.

A number of observations can be drawn from this table. First, it is clear that care must be taken when comparing services defined in different systems. For example, the terms "secondary response" (GB), "secondary control reserve" (UCTE), and "secondary reserve" (PJM) describe three completely different services. Even the term "reserve" may lead to some misunderstandings. For example, in Australia, "reserve" designates investments in generation capacity and not the frequency control reserves as defined in this paper. "Spinning reserve" is another example: California and PJM clearly use this term in different ways. Their definitions are also different from the one given by Wood and Wollenberg [4]: "the total synchronized capacity, minus the losses and the load." Indeed, the objectives considered, which are operational (California, PJM) or scheduling (Wood and Wollenberg), are different.

Besides differences in terminology, there are also significant differences in implementation. In Sweden, Great Britain, New Zealand, and Australia, the primary frequency control reserves have been divided in different categories. On the other hand, in the other systems, a single reserve is defined for this type of control. This difference may be explained by the fact that smaller systems are subject to larger frequency deviations than the large interconnected systems of North America and mainland Europe. Reserve that can be used for very fast primary frequency control reserve is therefore more valuable in these smaller systems, and making a distinction between different categories of primary reserve is technically and commercially worthwhile. Only one type of reserve is defined for performing secondary frequency control, except in Sweden and Great Britain, where secondary control is not used. Since the whole of the British system is operated by a single TSO (and is not synchronous with the Western European interconnected system), secondary control is not needed to correct deviations from interchange schedules. While Sweden is interconnected with other countries, its TSO can rely on numerous fast manual tertiary control offers provided by the large hydro generation capacity. Tertiary frequency control reserves do not lend themselves to easy comparison because TSOs have adopted widely different limits for deployment times and various approaches to the treatment of non-synchronized generating units.

\section{B. Voltage Control Service}

From a system perspective, the overall task of regulating the voltage is sometimes organized into a three-level hierarchy [3], [9]-[11], [37]. Primary voltage control is a local automatic control that maintains the voltage at a given bus (at the stator in the case of a generating unit) at its set point. Automatic voltage regulators (AVRs) fulfill this task for generating units [9]. Other controllable devices, such as static voltage compensators, can also participate in this primary control. Secondary voltage control is a centralized automatic control that coordinates the actions of local regulators in order to manage the injection of reactive power within a regional voltage zone. This uncommon technology is used in France and Italy [10], [11]. Tertiary voltage control refers to the manual optimization of the reactive power flows across the power system. In practice, because of the close link between voltage and reactive power in transmission networks, these three levels of control require that participating devices be able to generate or absorb reactive power.

From the perspective of providers of voltage control services, it is convenient to divide the production of reactive power into a basic and an enhanced reactive power service. The basic or compulsory reactive power service encompasses the requirements that generating units must fulfill to be connected to the network. The enhanced reactive power service is a non-compulsory service that is provided on top of the basic requirements. The terminology of voltage control is much more uniform than for frequency control and does not need to be discussed further.

\section{System Services and Ancillary Services}

It is sometimes useful to make a distinction between system services and ancillary services. System services are the services provided by the system operator to all users of the network, while ancillary services are the services supplied by some of the users of the network to the system operator [2]. To provide its system services, the system operator usually buys ancillary services from generators and consumers.

\section{TeChNiCAl Features of ANCILlary SERVICES}

This section first describes the main technical features that the various ancillary services listed in the previous section must have. It then compares the actual values required in the systems included in this survey. The comparison is centered on the UCTE interconnected system to illustrate the differences that can coexist within a single synchronous zone. The values for Great Britain (which is not synchronized with the UCTE) and NERC put this comparison into perspective. Only large generating units connected to the transmission network are considered here. Exceptions granted to small units and distributed generators are beyond the scope of this survey. The issues related to the transmission of data to and from the provider of ancillary services are not included in this survey either.

\section{A. Common Technical Features}

The most important technical parameters for frequency-related ancillary services are the deployment times. The maximum amount of time that can elapse between the request from the TSO and the beginning of the response by the service provider will be called the "deployment start." "Full availability" is the maximum time that can elapse between the moment when the provider receives the request and the moment at which it delivers its full response. Lastly, "deployment end" is the maximum amount of time during which the service must be provided starting from the time of the request. Note that the framework described in the previous section does not mention deployment times because these times vary too much between systems.

The accuracy of the measurements is another important issue because it affects the efficiency of the control and the payments 
TABLE III

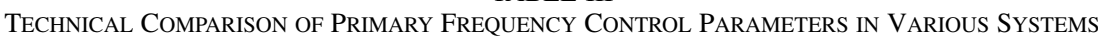

\begin{tabular}{|c|c|c|c|c|c|c|c|c|}
\hline & NERC & UCTE & $\mathrm{DE}$ & FR & ES & $\mathrm{NL}$ & $\mathrm{BE}$ & GB \\
\hline References & {$[24],[25],[26]$} & [29], [37] & {$[20],[21]$} & {$[18],[19]$} & [34] & {$[27],[28],[29]$} & [17] & {$[22],[23]$} \\
\hline $\begin{array}{l}\text { Full } \\
\text { availability }\end{array}$ & No rec. & $\leq 30 \mathrm{~s}$ & $\leq 30 \mathrm{~s}$ & $\leq 30 \mathrm{~s}$ & $\leq 30 \mathrm{~s}$ & $\leq 30 \mathrm{~s}$ & $\leq 30 \mathrm{~s}$ & $\begin{array}{l}\text { Pri.: } \leq 10 \mathrm{~s} \\
\text { Sec.: } \leq 30 \mathrm{~s} \\
\text { Hi.: } \leq 10 \mathrm{~s}\end{array}$ \\
\hline $\begin{array}{l}\text { Deployment } \\
\text { end }\end{array}$ & No rec. & $\geq 15 \mathrm{~min}$ & $\geq 15 \mathrm{~min}$ & $\geq 15 \mathrm{~min}$ & $\geq 15 \mathrm{~min}$ & $\geq 15 \mathrm{~min}$ & $\geq 15 \mathrm{~min}$ & $\begin{array}{l}\text { Pri.: } \geq 30 \mathrm{~s} \\
\text { Sec.: } \geq 30 \mathrm{~min} \\
\text { Hi.: as long as } \\
\text { required }\end{array}$ \\
\hline $\begin{array}{l}\text { Frequency } \\
\text { characteristic } \\
\text { requirement }\end{array}$ & \begin{tabular}{|c|}
$10 \%$ of the \\
balancing \\
authority's \\
estimated yearly \\
peak demand/Hz
\end{tabular} & $20,570 \mathrm{MW} / \mathrm{Hz}$ & $\approx 4,200 \mathrm{MW} / \mathrm{Hz}$ & $\approx 4,200 \mathrm{MW} / \mathrm{Hz}=$ & $\approx 1,800 \mathrm{MW} / \mathrm{Hz}$ & $\approx 740 \mathrm{MW} / \mathrm{Hz}$ & $\approx 600 \mathrm{MW} / \mathrm{Hz}$ & $z=\begin{array}{c}\text { Variable } \\
\approx 2,000 \mathrm{MW} / \mathrm{Hz}\end{array}$ \\
\hline $\begin{array}{l}\text { Droop of } \\
\text { generators }\end{array}$ & $\begin{array}{c}5 \% \text { in } 2004 ; \text { no } \\
\text { rec. anymore }\end{array}$ & No rec. & No rec. & $3-6 \%$ & $\leq 7.5 \%$ & $\begin{array}{l}5-60 \mathrm{MW}: 10 \% \\
>60 \mathrm{MW}: 4-20 \% \\
\end{array}$ & No rec. & $3-5 \%$ \\
\hline $\begin{array}{l}\text { Is an adjustable } \\
\text { droop } \\
\text { compulsory? }\end{array}$ & No rec. & No rec. & Yes & Yes & No rec. & $\begin{array}{l}\text { 5-60 MW: No rec. } \\
\text { > } 60 \mathrm{MW} \text { : Yes }\end{array}$ & No & Yes \\
\hline $\begin{array}{l}\text { Accuracy of } \\
\text { the frequency } \\
\text { measurement }\end{array}$ & No rec. & $\begin{array}{l}\text { Within } \\
\pm 10 \mathrm{mHz}\end{array}$ & $\begin{array}{l}\text { Within } \\
\pm 10 \mathrm{mHz}\end{array}$ & No rec. & No rec. & No rec. & $\begin{array}{l}\text { Within } \\
\pm 10 \mathrm{mHz}\end{array}$ & No rec. \\
\hline $\begin{array}{l}\text { Controller } \\
\text { insensitivity }\end{array}$ & \begin{tabular}{|l|}
$\mathrm{T}: \pm 36 \mathrm{mHz}$ in \\
2004; no rec. \\
anymore \\
NI: No rec. \\
$\mathrm{I}:$ No rec.
\end{tabular} & \begin{tabular}{|l|}
$\mathrm{T}: \pm 10 \mathrm{mHz}$ \\
$\mathrm{NI}:$ No rec. \\
$\mathrm{I}:$ should be \\
compensated \\
within the zone \\
\end{tabular} & $\begin{array}{l}\text { T: } \pm 10 \mathrm{mHz} \\
\mathrm{NI}: \text { No rec. } \\
\mathrm{I}: \pm 0 \mathrm{mHz}\end{array}$ & \begin{tabular}{|l|}
$\mathrm{T}: \pm 10 \mathrm{mHz}$ \\
$\mathrm{NI}:$ No rec. \\
$\mathrm{I}:$ should be \\
compensated \\
within the zone
\end{tabular} & $\begin{array}{l}\text { T: } \pm 10 \mathrm{mHz} \\
\text { NI: No rec. } \\
\text { I: } \pm 0 \mathrm{mHz}\end{array}$ & $\begin{array}{l}\text { 5-60 MW: T: } \pm 150 \mathrm{mHz} \\
\text { NI: No rec.; I: No rec. } \\
\text { > } 60 \mathrm{MW}: \mathrm{T}: \pm 10 \mathrm{mHz} \\
\mathrm{NI}: \pm 10 \mathrm{mHz} ; \mathrm{I}: \\
\pm 0 \mathrm{mHz}\end{array}$ & $\begin{array}{l}\mathrm{T}: \pm 10 \mathrm{mHz} \\
\mathrm{NI}: \pm 10 \mathrm{mHz} \\
\text { I: No rec. }\end{array}$ & $\begin{array}{l}\text { T: } \pm 15 \mathrm{mHz} \\
\text { NI: No rec. } \\
\text { I: No rec. }\end{array}$ \\
\hline \begin{tabular}{l|l} 
Full \\
deployment for \\
or before a \\
deviation of:
\end{tabular} & No rec. & $\pm 200 \mathrm{mHz}$ & $\pm 200 \mathrm{mHz}$ & $\pm 200 \mathrm{mHz}$ & $\pm 200 \mathrm{mHz}$ & $\begin{array}{l}5-60 \mathrm{MW}: \\
30 \% \text { for } \pm 150-200 \mathrm{mHz} \\
60 \mathrm{MW}: \\
70 \% \text { for } \pm 50-100 \mathrm{mHz}\end{array}$ & $\pm 200 \mathrm{mHz}$ & $\mid \begin{array}{l}\text { Pri.: }-800 \mathrm{mHz} \\
\text { Sec.: }-500 \mathrm{mHz} \\
\text { Hi.: }+500 \mathrm{mHz}\end{array}$ \\
\hline
\end{tabular}

No rec.: no recommendation; Pri., Sec. or Hi.: primary, secondary or high frequency response; I: intentional; NI: non intentional; T: total.

to the providers. For example, if the instrumentation at a generating unit overestimates the frequency, its response to frequency deviations will be inadequate, and the generating unit may be paid more than what it deserves. However, it is generally in the interest of producers to measure accurately so they can argue more persuasively with the TSO in case of a dispute.

\section{B. Technical Features of the Primary Frequency Control}

For a steady-state frequency deviation $\Delta f$ from the nominal frequency $f_{n}$, a generator participating to the primary control will change its generation by $\Delta P_{G}$. In the case of a generator, note that frequency is generally not measured from the network but through the rotation speed of the shaft. The droop $s_{G}$ of this generator, which is the gain of the feedback loop in the primary frequency controller, is then defined as follows [37]:

$$
s_{G}=-\left(\Delta f / f_{n}\right) /\left(\Delta P_{G} / P_{n}\right)
$$

where $P_{n}$ is the nominal generator output power. A lower droop increases the response of a unit but would cause more stress in the generating unit as it would react more strongly to each deviation. Moreover, a unit with a low droop is more likely to succeed in switching to islanded mode in case of a major disturbance. Adjusting the droop is not always easy because it often requires that the plant be shut down.

The frequency deviation for which the entire primary frequency reserve has to be deployed is also an important parameter. Indeed, using this information, the value of the droop, and (1), one can calculate the maximal share of the nominal power output that must be kept in reserve to provide the required primary frequency control power.

The frequency characteristic $\lambda_{\text {zone }}$ of a control area is defined as follows [37]:

$$
\lambda_{\text {zone }}=-\left(P_{\mathrm{ae}}-P_{\mathrm{se}}\right) / \Delta f
$$

where $P_{\mathrm{ae}}$ is the actual power exchange from the zone to all neighboring zones (a positive value represents an overall export) following a steady-state frequency deviation $\Delta f$ from the nominal frequency. $P_{\mathrm{se}}$ is the scheduled power exchange from the zone to all neighboring zones (a positive value represents exports). Therefore, the frequency characteristic represents the total action of the primary frequency control provided by generators and the self-regulating effect of the load. In North America, the terms of "Beta" or "frequency governing characteristic" are preferred to designate $\lambda_{\text {zone }}[5]$.

The insensitivity of a primary controller is the frequency band within which the controller does not change its output. Two insensitivities should be distinguished: the non-intentional insensitivity, which is intrinsic to the controller, and the intentional insensitivity, which is added on purpose. In Europe, the non-intentional insensitivity is sometimes simply called insensitivity while the intentional insensitivity is called dead band. The sum of these two insensitivities gives the total insensitivity. If two generators have different total insensitivities, it means that the one with the smallest insensitivity will participate to the primary frequency control before and probably more frequently than the other one.

Table III summarizes the primary frequency control parameters in eight different systems. Since units providing primary 
frequency control must respond immediately to a change in frequency, the "deployment start" does not appears in this table.

Deployment times are the same all across the systems within the UCTE because it is important to have a homogeneous response in the synchronous zone. On the other hand, NERC does not make any recommendations on the value of this parameter. A faster primary frequency control is used in Great Britain because the size of this system makes it more susceptible to frequency variations.

The frequency characteristic of the Eastern interconnection of North America was around $31000 \mathrm{MW} / \mathrm{Hz}$ in 2004 [5], [26]. The requirements for the national systems within the UCTE are estimated from their annual electricity production [12] and the total UCTE's requirement (20 570 MW/Hz [29]). Lastly, the frequency characteristic in Great Britain is estimated from requirements in the tendering process for primary frequency control service [23].

Within the UCTE, the full deployment of the primary frequency reserve must occur before a deviation of $\pm 200 \mathrm{mHz}$ has happened. Hence, TSOs with a tight requirement for the droop (i.e., a small droop, such as in France) would need to reserve a large headroom for their generating units if they want to provide continuously their primary frequency control until $\pm 200 \mathrm{mHz}$. However, in practice, units with a small droop attain their maximum before the limit of $\pm 200 \mathrm{mHz}$, so they do better than what the UCTE recommends. In Belgium and Germany, no general condition is applied to the droop as this parameter is agreed between the generators and the TSO during the procurement process. Lastly, the full deployment of the British primary frequency reserve happens for larger deviations than in the UCTE because the British power system has a smaller inertia.

Policies on controller insensitivity are similar in all systems, except in Great Britain, where the requirement is less strict. NERC has recently changed its policy and no longer recommends any insensitivity. Before, a total insensitivity of $36 \mathrm{mHz}$ ( $30 \mathrm{mHz}$ if a 50/60 coefficient is applied to account for the difference in nominal frequency) was required [24], which is three times the UCTE's requirements $(10 \mathrm{mHz})$. However, the UCTE requirement applies only to the controller [37], while NERC former recommendation was for the "governor" [24]. This last term is not formally defined, but in the common understanding, it includes both primary frequency controller and actuators (e.g., jacks and valve). Therefore, in this table, the insensitivity of the controller only and the combination of the controller and the generator unit are not distinguished. Finally, the accuracy of the frequency measurement is not addressed explicitly in most systems.

\section{Technical Features of the Secondary Frequency Control}

Secondary frequency control can be organized in three manners: centralized, pluralistic, or hierarchical [37]. In a centralized organization, the control is performed by a single controller for the whole control area. In a pluralistic organization, the system is split into independent zones, each of which having its own controller and regulating capacity. In a hierarchical organization, the organization is similar to the pluralistic approach, but a main controller coordinates the action of all the other controllers.

The area control error (ACE) of a zone is calculated as follows according to the UCTE (ACE $\left.\mathrm{UCTE}_{\mathrm{UC}}\right)$ or NERC $\left(\mathrm{ACE}_{\mathrm{NERC}}\right)$ :

$$
\begin{aligned}
\mathrm{ACE}_{\mathrm{UCTE}} & =P_{\mathrm{me}}-P_{\mathrm{se}}+K_{\mathrm{ri}}\left(f_{m}-f_{t}\right) \\
\mathrm{ACE}_{\mathrm{NERC}} & =P_{\mathrm{me}}-P_{\mathrm{se}}-10 B\left(f_{m}-f_{t}\right)-I_{\mathrm{ME}}
\end{aligned}
$$

where $K_{\text {ri }}$ is the $\mathrm{K}$-factor of the control area (in $\mathrm{MW} / \mathrm{Hz}$ and positive) and $B$ the frequency bias setting (in MW/0.1 Hz and negative). $K_{\mathrm{ri}}$ and $B$ are an overestimate of the frequency characteristic of the zone. An underestimate would indeed lead to a conflict between the primary and secondary frequency controls. $P_{\text {me }}$ is the measured value of the total power exchanged by the zone with other zones (a positive value represents exports). Note that $P_{\text {me }}$ is slightly different from $P_{\text {ae }}$ because of measurement errors. $f_{m}$ is the measured network frequency. $f_{t}$ is the target frequency, which can differ from the nominal frequency when controlling the synchronous time [37]. The additional term $I_{\mathrm{ME}}$ introduces a very small correction factor. This factor compensates the difference between the integration of the instantaneous power exchanged and the demand's energy measurements [25].

Secondary frequency control usually relies on a proportional integral (PI) controller, filters, and heuristics to bring the ACE back to zero. The exact configuration varies from a system to another [6], [7], [32], [37], so no specific algorithm is given in this paper.

Because of data management problems, the frequency and the power flows through interconnections are measured with discrete time steps. Therefore, the time steps of frequency and power exchanges measurements, as well as the cycle time of the controller, should be considered carefully. Shorter cycle times help to get a more efficient secondary control but also imply higher data management costs.

The speed of the effective frequency correction by the secondary control depends on the error size. Nevertheless, the frequency normally should begin to come back to its target value (neglecting the frequency oscillations) no later than the full deployment of the primary frequency reserve. Indeed, at that time, the balance between consumption and production should have been re-established using the primary frequency control, and the secondary frequency control should have started its action.

Table IV shows the parameters adopted for secondary frequency control in seven different systems. Great Britain is not included in this table because secondary frequency control is not used in that country.

Deployment times in European countries are generally smaller than what the UCTE recommends, probably to provide some additional margin or to remain consistent with former local policies. For its part, NERC does not give any specific direct recommendation. However, it imposes some performance criteria through its Disturbance Control Standard (DCS) and its Control Performance Standard (CPS) [25]. To give an example of U.S. practice, within PJM, the secondary frequency control power should be deployed within five minutes and for at least one hour [31].

With a requirement of $0.8 \mathrm{mHz}$ (coefficient of 50/60 applied), NERC recommends a more precise frequency measurement 
TABLE IV

TECHNICAL COMPARISON OF SECONDARY FREQUENCY CONTROL PARAMETERS IN VARIOUS SySTEMS

\begin{tabular}{|c|c|c|c|c|c|c|c|}
\hline & NERC & UCTE & $\mathrm{DE}$ & FR & ES & $\mathrm{NL}$ & $\mathrm{BE}$ \\
\hline References & {$[25]$} & [37] & {$[20],[21]$} & [19] & [34] & {$[27],[28]$} & [17] \\
\hline Deployment start & No rec. & $\leq 30 \mathrm{~s}$ & $\begin{array}{l}\text { Immediate or } \\
\leq 5 \mathrm{~min}\end{array}$ & $\leq 30 \mathrm{~s}$ & No rec. & $30 \mathrm{~s}-1 \mathrm{~min}$ & $\leq 10 \mathrm{~s}$ \\
\hline Full availability & No rec. & $\leq 15 \mathrm{~min}$ & $\leq 5 \mathrm{~min}$ & $\leq 430 \mathrm{~s}$ or $\leq 97 \mathrm{~s}$ & $\leq 300-500 \mathrm{~s}$ & $\leq 15 \mathrm{~min}$ & $\leq 10 \mathrm{~min}$ \\
\hline Deployment end & No rec. & $\begin{array}{l}\text { As long as } \\
\text { required }\end{array}$ & As long as required & $\begin{array}{l}\text { As long as } \\
\text { required }\end{array}$ & $\geq 15 \mathrm{~min}$ & $\begin{array}{c}\geq 15 \text { min and as } \\
\text { agreed }\end{array}$ & $\begin{array}{l}\text { As long as } \\
\text { required }\end{array}$ \\
\hline Control organisation & No rec. & No rec. & Pluralistic & Centralised & Hierarchical & Pluralistic & Centralised \\
\hline $\begin{array}{l}\text { Frequency } \\
\text { measurement }\end{array}$ & $\begin{array}{c}\varepsilon \leq 1 \mathrm{mHz} \\
\mathrm{T} \leq 6 \mathrm{~s}\end{array}$ & $\begin{array}{c}1.0 \leq \varepsilon \leq 1.5 \mathrm{mHz} \\
\mathrm{T}: \text { No rec. }\end{array}$ & $\begin{array}{c}1.0 \leq \varepsilon \leq 1.5 \mathrm{mHz} \\
\mathrm{T}=1 \mathrm{~s}\end{array}$ & $\begin{array}{c}\varepsilon \leq 1.0 \mathrm{mHz} \\
\mathrm{T}=1 \mathrm{~s}\end{array}$ & $\begin{array}{l}\varepsilon: \text { Unknown } \\
\qquad \mathrm{T}=2 \mathrm{~s}\end{array}$ & $\begin{array}{c}\varepsilon \leq 1.0 \mathrm{mHz} \\
\mathrm{T}=4 \mathrm{~s}\end{array}$ & $\begin{array}{l}\varepsilon \leq 1.0 \mathrm{mHz} \\
\text { T: Variable }\end{array}$ \\
\hline $\begin{array}{l}\text { Exchanges } \\
\text { measurement }\end{array}$ & $\begin{array}{c}\varepsilon \leq 1.3 \% \\
\mathrm{~T} \leq 6 \mathrm{~s}\end{array}$ & $\begin{array}{c}\varepsilon \leq 1.5 \% \\
\mathrm{~T} \leq 5 \mathrm{~s}\end{array}$ & $\begin{array}{c}\varepsilon \leq 1.5 \% \\
\mathrm{~T}=1 \mathrm{~s}\end{array}$ & $\begin{array}{l}\varepsilon \leq 1.5 \% \\
\mathrm{~T}=10 \mathrm{~s}\end{array}$ & $\begin{array}{c}\varepsilon: \text { Unknown } \\
\mathrm{T}=4 \mathrm{~s}\end{array}$ & $\begin{array}{c}\varepsilon \leq 0.5 \% \\
\mathrm{~T}=4 \mathrm{~s}\end{array}$ & $\begin{array}{c}\varepsilon \leq 0.5 \% \\
\text { T: Variable }\end{array}$ \\
\hline Controller cycle time & $\leq 6 \mathrm{~s}$ & $1-5 \mathrm{~s}$ & $1-2 \mathrm{~s}$ & $5 \mathrm{~s}$ & $4 \mathrm{~s}$ & $4 \mathrm{~s}$ & $5 \mathrm{~s}$ \\
\hline Controller type & No rec. & I or PI & PI & I & $\begin{array}{l}\mathrm{P} \text { or PI, depending on } \\
\text { the regulation zone }\end{array}$ & \begin{tabular}{|c|} 
PI, with additional \\
heuristics
\end{tabular} & PI \\
\hline Proportional term & No rec. & $0-0.5$ & Unknown & 0 & Unknown & 0.5 & $0-0.5$ \\
\hline Integral term & No rec. & $50-200 \mathrm{~s}$ & Unknown & $115-180 \mathrm{~s}$ & $100 \mathrm{~s}$ & $100-160 \mathrm{~s}$ & $50-200 \mathrm{~s}$ \\
\hline $\begin{array}{l}\text { K-factor for } \\
\text { measuring the ACE }\end{array}$ & $\begin{array}{l}\text { The frequency } \\
\text { characteristic }\end{array}$ & $\begin{array}{l}110 \% \text { of the } \\
\text { frequency } \\
\text { characteristic }\end{array}$ & Unknown & Unknown & Unknown & $900 \mathrm{MW} / \mathrm{Hz}$ & $\approx 660 \mathrm{MW} / \mathrm{Hz}$ \\
\hline
\end{tabular}

No rec.: no recommendation; $\varepsilon$ : accuracy; T: cycle time; P, I or PI: proportional, integral and proportional-integral controller.

than the $1.5-\mathrm{mHz}$ UCTE specification. Concerning cycle times of controllers, the German one is the smallest amongst the systems.

Unlike the UCTE, NERC does not make any particular recommendations regarding the design of the secondary frequency controller. Where these data are available, the proportional term is very small, while the integral term is about $100 \mathrm{~s}$. Contrary to the frequency characteristic requirements given in Table III, the $\mathrm{K}$-factor cannot be estimated because it represents the actual frequency response of the system, which is not publicly available data. This parameter can be variable in real-time in the U.S., whereas it is constant in Europe. As guidelines for the K-factor, UCTE asks a $10 \%$ overestimation of the frequency characteristic while NERC recommends the exact value.

\section{Technical Features of the Voltage Control}

Contrary to the primary frequency control, parameters of the primary voltage control cannot be compared between systems and even most of the time between units. Indeed, the parameters of the voltage controller must take into account the configuration of the surrounding network. However, the requirements in terms of reactive power can be compared, as they measure the ability of the unit to control voltage. To allow a benchmarking between systems, the reactive power requirement given at the terminals $Q_{\text {stator }}$ is converted to the point of delivery (POD) $Q_{\mathrm{POD}}$. The POD is the point owned by the producer that is the electrically closest to the transmission network. At nominal power, the reactive power absorbed by the auxiliaries, the step-up transformer, and the transmission line until the POD is usually around 15\% of the nominal apparent power $S_{n}$. Therefore, the power supplied by the generator to the network could be estimated by

$$
Q_{\mathrm{POD}} \approx Q_{\text {Stator }}-0.15 \times S_{n}
$$

where $S_{n}$ is equal to $P_{n} / \mathrm{pf}$, and pf is the power factor of the generator. Sometimes, reactive power requirements may be given for the dimensioning voltage $U_{\mathrm{dim}}$ instead of the nominal voltage of the network $U_{n}$. The dimensioning voltage is the actual average voltage at which the generating unit is connected, which may vary from $U_{n}$. The possible reactive power/voltage pairs are given by the U/Q diagram of the unit. To convert from the reactive power requirement at $U_{\mathrm{dim}}$ to the one at $U_{n}$, a typical U/Q diagram should be used, case by case. In this survey, we assume that $U_{\operatorname{dim}}$ and $U_{n}$ are equal.

Concerning deployment times, the primary voltage control is immediate and must operate continuously, as it maintains the voltage at its nominal value and insures stability.

From an accounting perspective, cycle times and accuracy are less important for the voltage control than for the frequency control, because the utilization cost of reactive power is generally seen as low [1]. However, for the stability of the system, the measurement accuracy and the parameters of the voltage controller should be considered carefully.

Most of the TSOs make recommendations regarding the effectiveness of the control and, in particular, the stability margins [17], [18], [20], [35]. However, these requirements were not considered in this survey because it focuses on features of ancillary service controls.

Table $\mathrm{V}$ shows the reactive power requirements in eight different systems. While these requirements are often specified using a complete $\mathrm{P} / \mathrm{Q}$ diagram, this table can only show the maximum requirements for $P_{n}$.

NERC and the UCTE do not give any recommendation on reactive power requirements because it is a local problem. Spanish requirements are quite low in comparison to the other systems in the table. Therefore, connecting conditions are less stringent on this point in Spain than in the other systems. However, reactive power connecting conditions do not imply that one system uses more or less reactive power than another one since TSOs can contract for additional reactive capabilities or use some of their own reactive power sources. For example, the British TSO owns a number of static compensators, which may explain the low British requirements in terms of reactive power production. Unfortunately, data concerning these additional capabilities are rarely public. 
TABLE V

TeChNical COMParison of Voltage CONTROL PARAmeters in VARious Systems

\begin{tabular}{|c|c|c|c|c|c|c|c|c|}
\hline & NERC & UCTE & $\mathrm{DE}$ & FR & ES & $\mathrm{NL}$ & $\mathrm{BE}$ & GB \\
\hline References & {$[25]$} & {$[37]$} & [20] & [18] & [35] & [27] & [17] & [22] \\
\hline $\begin{array}{l}\text { Absorption capability } \\
\text { requirement (lagging) }\end{array}$ & $\begin{array}{l}\text { No } \\
\text { rec. }\end{array}$ & $\begin{array}{l}\text { No } \\
\text { rec. }\end{array}$ & $\begin{array}{l}\mathrm{pf}=0.95 \text { or } 0.975 \text { at the } \\
\text { POD for Pn and Un }\end{array}$ & $\begin{array}{c}-0.35 \cdot \mathrm{Pn} \text { at the POD } \\
\text { for Pn and Udim }\end{array}$ & $\begin{array}{l}\mathrm{pf}=0.989 \text { at the } \\
\text { POD for Pn and Un }\end{array}$ & $\begin{array}{l}\mathrm{pf}=0.8 \text { at the } \mathrm{POD} \\
\text { for } \mathrm{Pn} \text { and } \mathrm{Un}\end{array}$ & $\begin{array}{l}-0.10 \cdot \mathrm{Pn} \text { at the } \\
\text { POD for } \mathrm{Pn} \text { and } \mathrm{Un}\end{array}$ & $\begin{array}{l}\mathrm{pf}=0.85 \text { at the } \\
\text { terminals for } \mathrm{Pn}\end{array}$ \\
\hline $\begin{array}{l}\text { Production capability } \\
\text { requirement (leading) }\end{array}$ & $\begin{array}{l}\text { No } \\
\text { rec. }\end{array}$ & $\begin{array}{l}\text { No } \\
\text { rec. }\end{array}$ & $\begin{array}{c}\mathrm{pf}=0.925 \text { or } 0.9 \text { at the } \\
\text { POD for Pn and Un }\end{array}$ & $\begin{array}{c}0.32 \cdot \mathrm{Pn} \text { at the POD } \\
\text { for Pn and Udim }\end{array}$ & $\begin{array}{c}\mathrm{pf}=0.989 \text { at the } \\
\text { POD for } \mathrm{Pn} \text { and } \mathrm{Un}\end{array}$ & $\begin{array}{l}\mathrm{pf}=0.8 \text { at the } \mathrm{POD} \\
\text { for } \mathrm{Pn} \text { and } \mathrm{Un}\end{array}$ & $\begin{array}{l}0.45 \cdot \mathrm{Pn} \text { at the POD } \\
\text { for Pn and Un }\end{array}$ & $\begin{array}{l}\mathrm{pf}=0.95 \text { at the } \\
\text { terminals for } \mathrm{Pn}\end{array}$ \\
\hline $\begin{array}{l}\text { Estimated absorption } \\
\text { requirement at the } \\
\text { POD for } \mathrm{Pn} \text { and Un }\end{array}$ & $\begin{array}{l}\text { No } \\
\text { rec. }\end{array}$ & $\begin{array}{l}\text { No } \\
\text { rec. }\end{array}$ & $-0.33 \cdot \mathrm{Pn}$ or $-0.23 \cdot \mathrm{Pn}$ & $-0.35 \cdot \mathrm{Pn}$ & $-0.15 \cdot \mathrm{Pn}$ & $-0.75 \cdot \mathrm{Pn}$ & $-0.10 \cdot \mathrm{Pn}$ & $-0.80 \cdot \mathrm{Pn}$ \\
\hline $\begin{array}{l}\text { Estimated production } \\
\text { requirement at the } \\
\text { POD for Pn and Un }\end{array}$ & $\begin{array}{l}\text { No } \\
\text { rec. }\end{array}$ & $\begin{array}{l}\text { No } \\
\text { rec. }\end{array}$ & $0.41 \cdot \mathrm{Pn}$ or $0.48 \cdot \mathrm{Pn}$ & $0.32 \cdot \mathrm{Pn}$ & $0.15 \cdot \mathrm{Pn}$ & $0.75 \cdot \mathrm{Pn}$ & $0.45 \cdot \mathrm{Pn}$ & $0.17 \cdot \mathrm{Pn}$ \\
\hline
\end{tabular}

No rec.: no recommendation; pf: power factor; Pn: nominal power; POD: Point Of Delivery; Udim: dimensioning voltage; Un: nominal voltage.

\section{CONCLUSION}

This paper has presented the technical fundamentals to compare the frequency and voltage control ancillary services markets. Differences in the terminology used for frequency control and reserves may lead to some confusion. So, by classifying within the European UCTE's framework the terms used in 11 systems, this paper provides a basis for a comparison of frequency control ancillary services across systems. This document also explains the important technical features that must be taken into account when procuring or trading frequency and voltage control ancillary services. Lastly, the specifications for these ancillary services in eight different systems are reviewed.

For security reasons, primary frequency control ancillary service must be uniformly spread around the network. Moreover, this service is a very differentiated product because of its multiple parameters such as the droop, the deployment times, the insensitivity of the controller, the accuracy of the measurements, or the deviation for which the full deployment is reached. On the other hand, because the controller of the secondary frequency control ancillary service is managed by the TSO, only deployment times are important, which results in a less differentiated product. However, there is no common practice since each system has different requirements on deployment times. The secondary frequency control ancillary service is very important, but its automatic feature is not always necessary, especially for non-interconnected systems. Lastly, the voltage control ancillary service is hard to compare across systems, as the configurations of the controllers depend on their location in the network. However, the reactive requirements are good indicators of the constraints put on producers by the TSO because of voltage control.

\section{ACKNOWLEDGMENT}

The authors would like to thank J. Apfelbeck, C. Bäck, N. Janssens, T. Kokkelink, T. Meister, B. Prestat, and R. Vice for their contributions. However, all errors, omissions, and inaccuracies remain the sole responsibility of the authors.

\section{REFERENCES}

[1] Y. G. Rebours, D. S. Kirschen, M. Trotignon, and S. Rossignol, "A survey of frequency and voltage control ancillary services-Part II: Economic features," IEEE Trans. Power Syst., vol. 22, no. 1, pp. 358-366, Feb. 2007.
[2] Eurelectric Connection Rules for Generation and Management of Ancillary Services, 2000-130-0003, May 2000. [Online]. Available: http://www.eurelectric.org/Download/Download.aspx?DocumentFileID $=4604$.

[3] P. Kundur, Power System Stability and Control. New York: McGrawHill, 1994.

[4] A. J. Wood and B. F. Wollenberg, Power Generation, Operation and Control, 2nd ed. New York: Wiley, 1996.

[5] J. W. Ingleson and D. M. Ellis, "Tracking the eastern interconnection frequency governing characteristic," in Proc. IEEE Power Eng. Soc. General Meeting, 2005, pp. 2484-2489.

[6] N. Jaleeli, L. S. VanSlyck, D. N. Ewart, L. H. Fink, and A. G. Hoffmann, "Understanding automatic generation control," IEEE Trans. Power Syst., vol. 7, no. 3, pp. 1106-1122, Aug. 1992.

[7] E. Jaggy and A. P. Longley, "Implementation of an AGC-algorithm in different power systems and on different control levels," in Proc. Inst. Elect. Eng. Int. Conf. Power System Monitoring Control, 1991, pp. $162-167$.

[8] L.-R. Chang-Chien, N.-B. Hoonchareon, C.-M. Ong, and R. A. Kramer, "Estimation of $\beta$ for adaptive frequency bias setting in load frequency control," IEEE Trans. Power Syst., vol. 18, no. 2, pp. 904-911, May 2003.

[9] IEEE Recommended Practice for Excitation System Models for Power System Stability Studies, IEEE Std. 421.5-2005, Apr. 2006.

[10] S. Corsi, P. Marannino, N. Losignore, G. Moreschini, and G. Piccini, "Coordination between the reactive power scheduling function and the hierarchical voltage control of the EHV ENEL system," IEEE Trans. Power Syst., vol. 10, no. 2, pp. 686-694, May 1995.

[11] H. Vu, P. Pruvot, C. Launay, and Y. Harmand, "An improved voltage control on large-scale power system," IEEE Trans. Power Syst., vol. 11, no. 3, pp. 1295-1303, Aug. 1996.

[12] IEA Energy Statistics Jun. 2005. [Online]. Available: http://www.iea. org/textbase/stats/electricityresult.asp.

[13] NEMMCO, Australia, Guide to Ancillary Services in the National Electricity Market, No 1.0, Aug. 24, 2001. [Online]. Available: http://www.nemmco.com.au/ancillary_services/160-0056.pdf.

[14] NEMMCO, Australia, Market Ancillary Service Specification, No 1.5 Final, Feb. 27, 2004. [Online]. Available: http://www.nemmco.com.au/ ancillary_services/160-0163.pdf.

[15] NEMMCO, Australia, Operating Procedure: Glossary , No SO_OP2000, Oct. 20, 2005. [Online]. Available: http://www.nemmco. com.au/powersystemops/so_op2000v011.pdf.

[16] CAISO, USA, Glossary of Terms Jan. 2006. [Online]. Available: http:// www.caiso.com/aboutus/glossary.

[17] Ministère des affaires économiques, "Arrêté royal établissant un règlement technique pour la gestion du réseau de transport de l'électricité et l'accès à celui-ci". Moniteur Belge, Belgium, 2002, pp. 58471-58541.

[18] Ministère de l'économie, des finances et de l'industrie, "Arrêté du 4 juillet 2003 relatif aux prescriptions techniques de conception et de fonctionnement pour le raccordement au réseau public de transport d'une installation de production d'énergie électrique," Journal Officiel de la République française $\mathrm{n}^{\circ} 201$ France, 2003, pp. 14896-14902.

[19] RTE, France, Mémento de la sûreté du système électrique 2004. [Online]. Available: http://195.101.127.20/htm/fr/qui/telecharge/memento_surete_2004/memento_surete_2004_complet_.pdf. 
[20] VDN, Germany, Transmission Code: Network and System Rules of the German Transmission System Operators, Aug. 2003. [Online]. Available: http://www.vdn-berlin.de/global/downloads/englisch/service/TransmissionCode2003engl.pdf.

[21] VDN, Germany, Transmission Code: Network and System Rules of the German Transmission System Operators-Appendices, Aug. 2003. [Online]. Available: http://www.vdn-berlin.de/global/downloads/englisch/service/TransmissionCode2003_Appendices_englisch.pdf.

[22] NGET, Great Britain, The Grid Code, Issue 3, Revision 11, Jul. 15, 2005. [Online]. Available: http://www.nationalgrid.com/uk/indinfo/grid_code/pdfs/zFull_GB_Grid_Code_I3R11.pdf.

[23] NGET, Great Britain, Firm Frequency Response: Market Information for Tenders for October 2005, Sep. 2005. [Online]. Available: http://www.nationalgrid.com/uk/indinfo/balancing/pdfs/ FFR\%20Market\%20Information\%200ct_v2.pdf.

[24] NERC, Operating Manual, Jun. 15, 2004. [Online]. Available: ftp:// www.nerc.com/pub/sys/all_updl/oc/opman/opman.pdf.

[25] NERC, Operating Manual, Dec. 7, 2005. [Online]. Available: ftp:// www.nerc.com/pub/sys/all_updl/oc/opman/New_OP_Manual_2.pdf.

[26] NERC, Frequency Response Standard Whitepaper, Jan. 17, 2005. [Online]. Available: ftp://www.nerc.com/pub/sys/all_updl/oc/rs/Frequency_Response_White_Paper.pdf,

[27] DTe, The Netherlands, Netcode, Jul. 1, 2005. [Online]. Available: http://www.dte.nl/images/NETCODE\%20per\%2001072005_tcm774895.pdf.

[28] TenneT, The Netherlands, Samenvatting uit "Summary of the Current Operating Principles of the UCPTE" met betrekking tot de primaire en secundaire regeling, Dec. 2003. [Online]. Available: http://www. tennet.org/english/images/UCTE-regels_tcm15-1742.pdf.

[29] TenneT, The Netherlands, Primary Reserve, Jan. 2006. [Online]. Available: http://www.tennet.org/english/system_services/primary/.

[30] NZIER, New Zealand, Market Design Report: Initial Stock-take Paper Report to the Electricity Commission, Aug. 2005. [Online]. Available: http://www.electricitycommission.govt.nz/pdfs/opdev/ wholesale/market-design/Initial-Stocktake.pdf.

[31] PJM, USA, Manual 10: Pre-Scheduling Operations, Revision: 16, 2003. [Online]. Available: http://www.pjm.com/contributions/ pjm-manuals/ pdf/m10v161.pdf.

[32] PJM, USA, Manual 12: Dispatching Operations, Revision: 13, May 26, 2006. [Online]. Available: http://www.pjm.com/contributions/pjmmanuals/pdf/m12v13.pdf.

[33] PJM, USA, Manual 35: Definitions and Acronyms, Revision: 05, 2005. [Online]. Available: http://www.pjm.com/contributions/pjm-manuals/ pdf/m35v051.pdf.

[34] Ministerio de industria y energía, Spain, "Resolución de 30 de julio de 1998, de la Secretaria de Estado de Energía y Recursos Minerales, por la que se aprueba un conjunto de procedimientos de carácter técnico e instrumental necesarios para realizar la adecuada gestión técnica del sistema eléctrico," BOE n 197, 20053, Aug. 18, 1998, pp. 28158-28183.
[35] Ministerio de industria y energía, Spain, "Resolucion de 10 de marzo de 2000, de la Secretaría de Estado de Industria y Energía, por la que se aprueba el procedimiento de operación del sistema (P.O. - 7.4) «Servicio complementario de control de tensión de la red de transporte》,"Spain, BOE n 67, 5204, Mar. 18, 2000, pp. 11330-11346.

[36] NORDEL, Sweden, Nordic Grid Code (Nordisk regelsamling), Jun. 18, 2004.

[37] UCTE Operation Handbook, v 2.5E, UCTE, July 20, 2004. [Online]. Available: http://www.ucte.org/pdf/ohb/Operation_Handbook_20.07. 2004.pdf.

Yann G. Rebours (S'06) received the electrical engineer's degree from the Ecole Supérieure d'Electricité, Paris, France, and the master's degree in electrical engineering from the University of Wollongong, Wollongong, Australia, in 2004. He is currently pursuing the Ph.D. degree at the University of Manchester, Manchester, U.K.

Daniel S. Kirschen (M'86-SM'92-F'07) received the electrical and mechanical engineer's degree from the Université Libre de Bruxelles, Bruxelles, Belgium, in 1979 and the master's and Ph.D. degrees from the University of Wisconsin-Madison in 1980 and 1985, respectively.

Between 1985 and 1994, he worked for Control Data Corporation, Empros Systems International, and Siemens Energy and Automation. He is currently a Professor of electrical energy systems at the University of Manchester, Manchester, U.K.

Marc Trotignon received the graduated engineer degree in 1979 from the Ecole Centrale, Paris, France.

$\mathrm{He}$ is currently Project Manager at EDF Research and Development, Clamart, France, coordinating several research projects dealing with regulation and market design. He has previously worked on power system dynamics, reliability issues, and interconnection. His main areas of interest are at the crossroads of economic, technical, and legal matters and concern some of the questions the power industry has to tackle in its new competitive organization: resource adequacy policies, interaction with environmental constraints, management of network congestion, and procurement and pricing of ancillary services.

Sébastien Rossignol received the engineering degree from the Ecole Supérieure d'Electricité, Paris, France, in 2001.

$\mathrm{He}$ is currently a Research Engineer and Project Manager at EDF Research and Development, Clamart, France, in the power systems dynamics and grid connections group. He is in charge of studies in the field of ancillary services and dynamic stability studies. 